CONTROVERSIAL ISSUES \& CURRENT CONCEPTS

\title{
Surgical versus conservative treatment for torn anterior cruciate ligament
}

\author{
O. Şahap Atik, MD (1) \\ Professor of Orthopedic Surgery, Turkish Joint Diseases Foundation, Ankara, Turkey
}

Ideal conditions for healing are mostly non-existent in one of the most common sports-related injury, the anterior cruciate ligament (ACL) tear. ${ }^{[1]}$ Furthermore, there are still controversies in regards to the optimal management of a torn ACL. Anterior cruciate ligament rupture has major consequences at midterm follow-up, with an increasing chance of developing an old knee in a young patient.

At five years, patients treated with ACL reconstruction versus rehabilitation alone did not differ in quadriceps strength, performance on single-legged hop tests, activity level, pain, symptoms, and activities of daily living, knee-related quality of life or presence of knee osteoarthritis. ${ }^{[2]}$

Is it rational to recommend surgical reconstruction of the torn ACL to every patient? At present, there is no evidence-based argument to recommend surgical reconstruction alone as an optimal option to any patient who tore his ACL. Knee stability can be improved not only by surgery but also by neuromuscular rehabilitation; whatever the treatment, fully normal knee kinematics are not restored. ${ }^{[3]}$

In a retrospective pair-matched study, in 20-year follow-up, there was no difference in knee osteoarthritis between operative versus conservative treatment. Although knee stability was better in the

Received: December 08, 2019

Accepted: January 01, 2020

Published online: March 02, 2020

Correspondence: O. Şahap Atik, MD. Turkish Joint Diseases Foundation, Mustafa Kemal Mah., Dumlupınar Bul., 274/2, C2 Blok, Ofis 5, 06900 Çankaya, Ankara, Türkiye.

E-mail: satikmd@gmail.com

Doi: $10.5606 /$ ehc. 2020.57892

Citation: Atik OS. Surgical versus conservative treatment for torn anterior cruciate ligament. Jt Dis Relat Surg 2020;31(1):159-160. operative group, it did not result in better subjective and objective functional outcomes. Knee osteoarthritis was found in $80 \%$ of the operative group compared with $68 \%$ of the conservative group ${ }^{[4]}$

Biomechanical evaluation of a jump-landing task was performed before and after completion of the program in a study to search the efficacy of a neuromuscular training program to ameliorate known hip biomechanical risk factors for athletes with ACL reconstruction. It was determined that known hip biomechanical risk factors of ACL injury were significantly reduced among athletes with ACL reconstruction after the neuromuscular training program and that post-training hip biomechanics between the ACL reconstruction and control cohorts were not different. ${ }^{[5]}$

Athletes who return to sports after ACL reconstruction demonstrate persistent biomechanical and neuromuscular deficits of the knee. Significant improvements in knee sagittal plane biomechanical measures were observed after the neuromuscular training program by athletes with ACL reconstruction. In addition, post-training comparison of the ACL reconstruction and control groups demonstrates comparable knee biomechanics. ${ }^{[6]}$

Reconstruction of the ACL is not a prerequisite for restoring the muscle function; however, restoring muscle function is a prerequisite for conservative or surgical treatment of the torn ACL. ${ }^{[7]}$

In conclusion;

- There are some indications for non-surgical treatment with a strict neuromuscular rehabilitation program.

- Neuromuscular rehabilitation is also necessary prior to and after ACL reconstruction.

- This is crucial for primary and secondary preventions as well. 


\section{Declaration of conflicting interests}

The author declared no conflicts of interest with respect to the authorship and/or publication of this article.

\section{Funding}

The author received no financial support for the research and/or authorship of this article.

\section{REFERENCES}

1. Sezgin EA, Atik OŞ. Are orthobiologics the next chapter in clinical orthopedics? A literature review. Eklem Hastalik Cerrahisi 2018;29:110-6.

2. Wellsandt E, Failla MJ, Axe MJ, Snyder-Mackler L. Does anterior cruciate ligament reconstruction improve functional and radiographic outcomes over nonoperative management 5 years after injury? Am J Sports Med 2018;46:2103-12.

3. Delincé P, Ghafil D. Anterior cruciate ligament tears: conservative or surgical treatment? A critical review of the literature. Knee Surg Sports Traumatol Arthrosc 2012;20:48-61.

4. van Yperen DT, Reijman M, van Es EM, Bierma-Zeinstra SMA, Meuffels DE. Twenty-year follow-up study comparing operative versus nonoperative treatment of anterior cruciate ligament ruptures in high-level athletes. Am J Sports Med 2018;46:1129-36.

5. Nagelli C, Wordeman S, Di Stasi S, Hoffman J, Marulli T, Hewett TE. Biomechanical deficits at the hip in athletes with acl reconstruction are ameliorated with neuromuscular training. Am J Sports Med 2018;46:2772-9.

6. Nagelli CV, Wordeman SC, Di Stasi S, Hoffman J, Marulli T, Hewett TE. Neuromuscular training improves biomechanical deficits at the knee in anterior cruciate ligament-reconstructed athletes. Clin J Sport Med. 2019.

7. Atik OŞ. What is the role of the conservative intervention in the treatment of a torn anterior cruciate ligament? Eklem Hastalik Cerrahisi 2015;26:97-9. 